\title{
Tumor mesenquimal de mediastino
}

\author{
Mesenchymal mediastinal tumor
}

Juan Manuel Gómez-Cerquera, Estefany Roxana Cruz-Valderrama

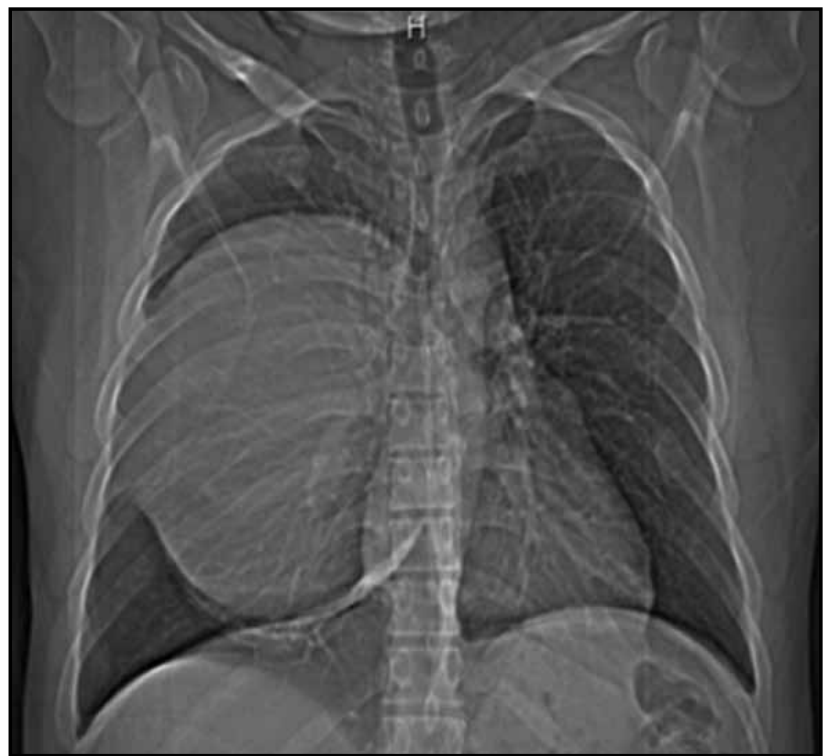

Figura 1. Radiografía de tórax.

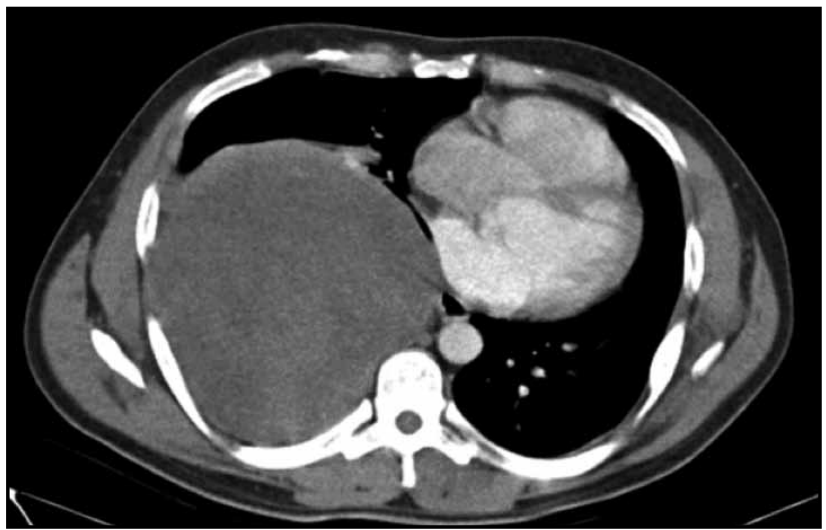

Figura 2. Tomografía axial computarizada de tórax.

Varón de 40 años con cuadro clínico de seis meses de dolor en hemitórax derecho, opresivo, intermitente, de intensidad moderada, asociado a disnea de medianos esfuerzos. En el examen físico destaca una disminución del murmullo vesicular en hemitórax derecho.

Dr. Juan Manuel Gómez-Cerquera: Departamento de Medicina Interna, Estefany Roxana Cruz-Valderrama. Facultad de Ciencias de la Salud, Fundación Universitaria Navarra - UNINAVARRA. Neiva-Huila (Colombia).

Correspondencia: Estefany Roxana Cruz-Valderrama. Neiva-Huila (Colombia). E-mail: estefanyc57@gmail.com

Recibido: 10/IX/2018 Aceptado: 7/III/2019

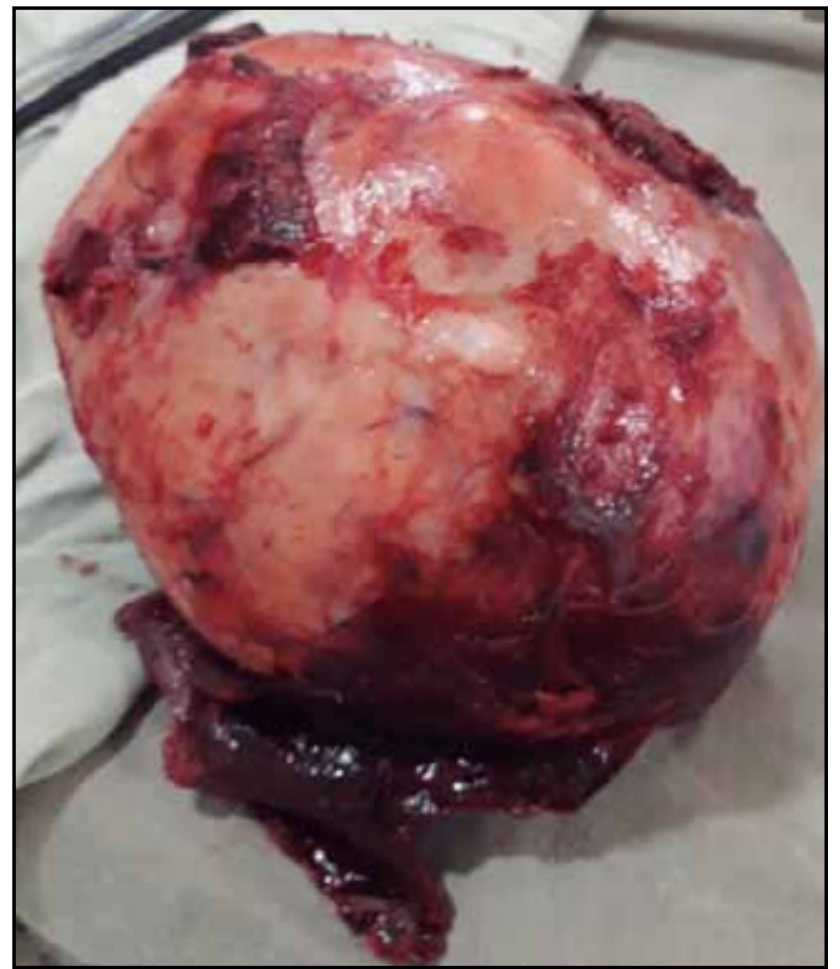

Figura 3. Pieza quirúrgica de la masa resecada.

Se realiza radiografía de tórax (Figura 1) que evidencia una masa de $15 \times 13 \mathrm{~cm}$, bordes bien definidos, de localización extrapulmonar, que desplaza las estructuras mediastínicas. La tomografía axial computarizada de tórax (Figura 2) confirma los hallazgos; se realiza biopsia de la lesión y el estudio histopatológico concluye el diagnóstico de tumor mesenquimal fusocelular. El paciente es llevado a cirugía, logrando la resección total del tumor sin complicaciones (Figura 3).

Los tumores mesenquimales de mediastino son bastante raros y representan sólo $2 \%$ de todos los tumores mediastínicos. La sintomatología suele ser muy variada, desde pacientes asintomáticos hasta síntomas severos principalmente si el efecto compresivo es importante.

\section{Referencias}

1. Den Bakker, Michael A. et al. Mesenchymal Tumours of the Mediastinum - part I. Virchows Archiv 467 (2015): 487-500. PMC. Web. 19 Aug. 2018.

2. Den Bakker, Michael A. et al. Mesenchymal Tumours of the Mediastinum - part II. Virchows Archiv 467 (2015): 501-517. PMC. Web. 19 Aug. 2018. 